\title{
Clinical Profile of Patients with Chronic Kidney Disease
}

\author{
Karan VN', Vishwanath VN² \\ ${ }^{1}$ Senior Resident, Department of General Medicine, Mahaveer Institute of Medical Sciences, Vikarabad, Telangana, ${ }^{2}$ Associate Professor, Department of \\ General Medicine, KBNIMS, Gulbarga, Karnataka.
}

\section{Abstract}

Background: DM is the leading cause of end-stage renal disease (ESRD), non-traumatic lower extremity amputations, and adult blindness. It also predisposes to cardiovascular diseases. With an increasing incidence worldwide, DM will be likely a leading cause of morbidity and mortality in the future ${ }^{29}$. Chronic kidney disease (CKD) encompasses a spectrum of different pathophysiologic processes associated with abnormal kidney function and a progressive decline in glomerular filtration rate. Subjects and Methods: A written informed consent was obtained from all patients. History regarding the duration of hypertension, the medications being taken, coexisting medical problems, and symptomatology suggestive of ischemic heart disease, transient ischemic attacks and that of renal involvement were documented. A detailed history, anthropometry, vital signs, clinical examination and laboratory parameters were recorded for both the study group. Results: The Study reveals that, there was statistically very highly significant difference of age among Type 2 diabetes mellitus with CKD and Non-diabetic patients with CKD $(\mathrm{P}<0.001)$. Type 2 diabetes mellitus with CKD cases had significantly higher mean age as compare to Non-diabetic patients with CKD cases. Conclusion: There was statistical significant difference of mean serum uric acid among vegetarians and non-vegetarians with CKD patients $(\mathrm{P}>0.05)$.It's found that vegetarians have less SUA level when compare to mixed diet patients.

Keywords: Chronic kidney disease, DM, GFR.

Corresponding Author: Dr. Vishwanath VN, Associate Professor, Department of General Medicine, KBNIMS, Gulbarga, Karnataka.

Received: December 2019

Accepted: December 2019

\section{Introduction}

Diabetes mellitus (DM) refers to a group of common metabolic disorders that share the phenotype of hyperglycemia. Several distinct types of DM are caused by a complex interaction of genetics and environmental factors. Depending on the etiology of the DM, factors contributing to hyperglycemia include reduced insulin secretion, decreased glucose utilization, and increased glucose production. The metabolic dysregulation associated with DM causes secondary pathophysiologic changes in multiple organ systems that impose a tremendous burden on the individual with diabetes and on the health care system. In the United States, DM is the leading cause of end-stage renal disease (ESRD), non-traumatic lower extremity amputations, and adult blindness. It also predisposes to cardiovascular diseases. With an increasing incidence worldwide, DM will be likely a leading cause of morbidity and mortality in the future.

Chronic kidney disease (CKD) encompasses a spectrum of different pathophysiologic processes associated with abnormal kidney function and a progressive decline in glomerular filtration rate (GFR). ${ }^{[1]}$

The pathophysiology of CKD involves two broad sets of mechanisms of damage: (1) initiating mechanisms specific to the underlying etiology (e.g., genetically determined abnormalities in kidney development or integrity, immune complex deposition and inflammation in certain Types of glomerulonephritis, or toxin exposure in certain diseases of the renal tubules and interstitium) and (2) a set of progressive mechanisms, involving hyperfiltration and hypertrophy of the remaining viable nephrons, that are a common consequence following long-term reduction Of renal mass, irrespective of underlying etiology. The responses to reduction in nephron number are mediated by vasoactive hormones, cytokines, and growth factors. Eventually, these short-term adaptations of hypertrophy and hyperfiltration become maladaptive as the increased pressure and flow within the nephron predisposes to distortion of glomerular architecture, abnormal podocytefunction, and disruption of the filtration barrier leading to sclerosis and dropout of the remaining nephrons. Increased intrarenal activity of the renin-angiotensin system (RAS) appears to contribute both to the initial adaptive hyperfiltration and to the subsequent maladaptive hypertrophy and sclerosis. This process explains why a reduction in renal mass from an isolated insult may lead to a progressive decline in renal function over many years. ${ }^{[2]}$

Hypovitaminosis A and other nutritional issues during pregnancy may cause smaller kidney volume at birth and a lower eGFR.Consanguinity and genetic inbreeding increase risk of congenital anomalies of the kidney and urinary tract and obstructive or reflux nephropathy.Poverty, poor sanitation, pollutants, water contamination, overcrowding, and known and unknown nephrotoxins (including heavy metals and plant toxins in indigenous remedies) may lead to 
glomerular and interstitial kidney diseases. Added to these exposuresare the growing burden of hypertension and diabetes mellitus. By 2030, India is expected to have the world's largest population of patients with diabetes. ${ }^{[3]}$

Because of challenges in access to care, over $50 \%$ of patients with advanced CKD are first seen when the eGFRis ,15 $\mathrm{ml} / \mathrm{min}$ per $1.73 \mathrm{~m} 2$. This sobering number highlights the need for robust screening programs for those at risk for CKD. The reported prevalence of CKD in different regions ranges from, $1 \%$ to $13 \%$, and recently, data from the International Society of Nephrology's Kidney Disease Data Center Study reported a prevalence of $17 \%$. The etiology of CKD varies considerably throughout India. Parts of the states of Andhra Pradesh, Odisha, and Goa have high levels of CKD of unknown etiology ( $\mathrm{CKDu})$, which is a chronic interstitial nephropathy with insidious onset and slow progression. ${ }^{[4]}$

The true burden of ESKD in India is not known,with few dedicated centers for care, lack of universal access to RRT, and absence of a registry. Even today,over $90 \%$ of patients requiring RRT in India die because of inability to afford care, and even in those who do start RRT, 60\% stop for financial reasons.Among patients who undergo kidney transplantation,unexpected complications have the potential to impose serious financial hardships

Hemodialysis (HD) was introduced in India in 1962,transplantation was introduced in 1971, and peritoneal dialysis (PD) was introduced in 1991. As of 2017, RRT is predominantly a private health care-driven initiative.There are over 130,000 patients receiving dialysis, and the number is increasing by about 232 per million population, a reflection of increasing longevity in general. Early immunization against hepatitis B is implemented in less than one quarter of patients with advanced CKD, and only a few have adequate titers of protective hepatitis B surface antibodies. Patients referred late are often anemic, have lower likelihood of hepatitis B immunization, start dialysis without an arteriovenous fistula, and have poorer prognosis and higher mortality at dialysis initiation. Protein energy wasting is present in $68 \%-93 \%$ of patients on dialysis from middle and lower socioeconomic strata. ${ }^{[5]}$

$\mathrm{HD}$ is the most common modality followed by transplantation, and PD is a distant third. India is estimated to have about 120,000 patients on HD. The recurring cost of a session of HD is approximately $\$ 9-\$ 45$ (without costs for allotted space and machines),but expenses incurred by the patient vary greatly.

The urban locations of HD units make PD attractive for the majority of rural patients, but lack of health insurance coverage and prohibitively expensive recurring costs (approximately \$350-\$400 monthly) are deterrents. Despite these barriers, PD utilization is increasing. India is estimated to have over 8500 patients on PD. Timely supply of PD fluid to remote regions across mountainous terrains and villages without adequate road access and hospital access for evaluation and treatment of PD-related infections are important challenges. The problems of unhygienic living conditions and nonavailability of a separate clean room for PD (especially for those living in mud huts) are being addressed. In areas where clean running water is unavailable for hand washing before doing a PD exchange,patients are taught to use water with dilute potassium permanganate solution instead. ${ }^{[6]}$

Transplantation practices are dependent on state welfare funding, brain death declaration practice, personal religious beliefs, and availability of technical expertise and expensive immunosuppressive medication. Living donor kidney transplantation far exceeds deceased donor transplantation.However, despite its cost-effectiveness, high initial costs and limited availability of living related donors are barriers. The imbalance between availability of organs and the need for transplantation has led to the regrettable unregulated practice of illegal living donor transplants in several south Asian countries, including India. Furthermore,infections are an important cause of mortality in transplant recipients.

\section{Subjects and Methods}

A written informed consent was obtained from all patients. History regarding the duration of hypertension, the medications being taken, coexisting medical problems, and symptomatology suggestive of ischemic heart disease, transient ischemic attacks and that of renal involvement were documented.

A detailed history, anthropometry, vital signs, clinical examination and laboratory parameters were recorded for both the study group.

- Height: Height was measured with the help of a metric scale attached to a vertical board. The individual was made to stand bare foot. Measurement was recorded to the nearest $0.1 \mathrm{~cm}$

- Weight: Dial type bathroom scale weighing machine was used for weight measurement. Weight was measured in kilogram.

- Body mass index: Calculated using Quetelet index

- Waist circumference, hip circumference and waist hip ratio: Waist and hip measurementswere made as per the ATP III guidelines. The Waist: Hip ratio was then calculated. The Waist-hip ratio or waist-to-hip ratio (WHR) is the dimensionless ratio of the circumference of the waist to that of the hips.

- Blood pressure recording: Sphygmomanometer is used to record the BP. BP is recorded in the sitting posture in the right upper limb using a proper sized cuff. Phase I Korokoff sound was taken as the systolic BP and disappearance of sound (phase IV) was taken as the diastolic BP. The blood pressure was measured at the time of enrollment. The average of their BP recorded in the last 6 months, if present was noted. With the patient in a seated position and after a 5-minuterest, BP was measured on the right arm with a mercury sphygmomanometer (cuff size, $12.5 \times 40 \mathrm{~cm}$ ). The systolic pressure and diastolic pressure were read to the nearest $2 \mathrm{~mm} \mathrm{Hg}$.

- Coronary artery disease: Cases are said to have coronary artery disease with any one of the following.

I. Past history of coronary artery disease with a documented evidence

II. ECG changes of past or present myocardial infarction confirmed by an echocardiography by an experienced cardiologist. 
Detailed history regarding patient's education, occupation, family income, daily physical activities, smoking, alcohol intake and family history of hypertension were asked. The socioeconomic status of the patient was determined using "Modified Kuppuswamy scale".

Participants with daily physical activity of - 2 MET (Metabolic Equivalent of Task) were considered as sedentary. Those who smoke -5 cigarettes » day were considered as smokers.Investigations included complete blood count, Renal function test (RFT), serum uric acid levels and lipid profile. Serum uric acid levels were measured using phosphotungstic acid method, caraway method. Study was undertaken after Institutional ethics committee approval and informed written consent from the subjects.

A detailed history of smoking (pack years / smoking index) and alcoholism (number of alcohol units per week was recorded; 1 alcohol unit=300 $\mathrm{ml}$ of beer, $100 \mathrm{ml}$ of wine, or $30 \mathrm{ml}$ of liquor) was obtained. A family history of cardiovascular and renal disease was noted. An overall clinical examination was done to exclude major comorbidities. Examination of the heart and the peripheral pulses including the carotids were made. Abdominal examination was done to look for renal bruit. The blood pressure was measured at the time of enrollment.

The presence, type, and extent of hypertensive retinopathy were investigated in a darkened room and under pupil dilatation. Direct ophthalmoscopy was carried out with an ophthalmoscope. The first arteriovenous crossing at least one disc diameter from the disc in each quadrant was selected and assessed for the presence of focal arteriolar narrowing, hemorrhages, exudates, and papilledema. Retinal lesions were classified according to the Keith-Wagner- Barker classification.

\section{Results}

\begin{tabular}{|c|c|c|c|c|c|c|}
\hline \multirow[t]{2}{*}{ Age in years } & \multicolumn{2}{|c|}{\begin{tabular}{|c} 
Type 2 Diabetes \\
mellitus with \\
CKD
\end{tabular}} & \multicolumn{2}{|c|}{$\begin{array}{c}\text { Non-diabetic } \\
\text { patients with CKD }\end{array}$} & \multicolumn{2}{|c|}{ Total } \\
\hline & No. & $\%$ & No. & $\%$ & No. & $\%$ \\
\hline$<30$ & 0 & 0.0 & 10 & 31.3 & 10 & 15.6 \\
\hline $30-39$ & 3 & 9.4 & 5 & 15.6 & 8 & 12.5 \\
\hline $40-49$ & 12 & 37.5 & 8 & 25.0 & 20 & 31.3 \\
\hline $50-59$ & 11 & 34.4 & 6 & 18.7 & 17 & 26.5 \\
\hline$>60$ & 6 & 18.7 & 3 & 9.4 & 9 & 14.1 \\
\hline Total & 32 & 100.0 & 32 & 100.0 & 64 & 100.0 \\
\hline Mean \pm SD & \multicolumn{2}{|c|}{$51.59 \pm 9.81$} & \multicolumn{2}{|c|}{$39.72 \pm 14.03$} & \multicolumn{2}{|c|}{$45.65 \pm 11.92$} \\
\hline \begin{tabular}{|l|}
$t$ - test P-value \\
$\&$ \\
Significance \\
\end{tabular} & $\mathrm{t}=3.92$, & $\mathrm{P}=0.00$ & $0, \mathrm{VHS}$ & & & \\
\hline
\end{tabular}

The Study reveals that, there was statistically very highly significant difference of age among Type 2 diabetes mellitus with CKD and Non-diabetic patients with CKD $(\mathrm{P}<0.001)$.Type 2 diabetes mellitus with CKD cases had significantly higher mean age as compare to Non-diabetic patients with CKD cases.
Table 2: Sex wise distribution of cases

\begin{tabular}{|l|l|l|l|l|l|l|}
\hline \multirow{2}{*}{ Age in years } & $\begin{array}{l}\text { Type 2 Diabetes } \\
\text { mellitus with } \\
\text { CKD }\end{array}$ & \multicolumn{2}{|c|}{$\begin{array}{c}\text { Non-diabetic } \\
\text { patients with } \\
\text { CKD }\end{array}$} & \multicolumn{2}{|c|}{ Total } \\
\cline { 2 - 7 } & NO. & $\%$ & NO. & $\%$ & NO. & $\%$ \\
\hline Males & 16 & 50.0 & 23 & 71.8 & 39 & 60.9 \\
\hline Females & 16 & 50.0 & 9 & 28.2 & 25 & 39.1 \\
\hline Total & 32 & 100.0 & 32 & 100.0 & 64 & 100.0 \\
\hline $\begin{array}{l}\square^{2} \text { - test P- } \\
\text { value } \\
\& \\
\text { significance }\end{array}$ & $\square^{2}=3.21$, P>0.05, NS & & & \\
\hline $\begin{array}{l}\text { NS= not significant, S=significant, HS=highly significant, VHS=very highly } \\
\text { significant }\end{array}$
\end{tabular}

The Study reveals that, there was no statistical significant difference among sex Type 2 diabetes mellitus with CKD and Non-diabetic patients with CKD $(\mathrm{P}>0.05)$.

Table 3: Comparison of mean serum uric acid in relation with diet practice

\begin{tabular}{|l|l|l|l|l|}
\hline \multirow{1}{*}{ Groups } & \multicolumn{2}{|c|}{ Serum uric acid } & \multirow{2}{*}{$\begin{array}{c}\text { t- test } \\
\text { values }\end{array}$} & $\begin{array}{c}\text { P-value \& } \\
\text { significance }\end{array}$ \\
\cline { 2 - 3 } & Vegetarian & Mixed diet & & \\
\cline { 2 - 3 } & Mean \pm SD & Mean \pm SD & & \\
\hline $\begin{array}{l}\text { Type 2 diabetes } \\
\text { mellitus with CKD }\end{array}$ & $7.43 \pm 2.23$ & $10.41 \pm 3.51$ & $\mathrm{t}=2.16$ & $\mathrm{P}=0.043, \mathrm{~S}$ \\
\hline $\begin{array}{l}\text { Non-diabetic patients } \\
\text { with CKD }\end{array}$ & $6.97 \pm 1.94$ & $9.43 \pm 2.45$ & $\mathrm{t}=2.25$ & $\mathrm{P}=0.032, \mathrm{~S}$ \\
\hline
\end{tabular}

There was statistical significant difference of mean serum uric acid among vegetarians andnon-vegetarians with CKD patients $(\mathrm{P}>0.05)$.It's found that vegetarians have less SUA levelwhen compare to mixed diet patients.

\begin{tabular}{|l|c|c|c|}
\hline \multicolumn{1}{|c|}{ Table 4: Comparison of serum uric in relation blood pressure } \\
\hline \multicolumn{1}{|c|}{ Groups } & \multicolumn{2}{|c|}{ Serum uric acid } & \multicolumn{1}{c|}{$\begin{array}{c}\text { P-value } \boldsymbol{B} \\
\text { significance }\end{array}$} \\
\cline { 2 - 3 } & Stage I & \multicolumn{1}{|c|}{ Stage II } & \\
\cline { 2 - 3 } & Mean \pm SD & Mean \pm SD & \\
& & & \\
\hline $\begin{array}{l}\text { Type 2 diabetes } \\
\text { mellituswith CKD }\end{array}$ & $\begin{array}{l}\text { No. of cases-13) } \\
9.07 \pm 4.15\end{array}$ & $\begin{array}{l}\text { No. of cases -19) } \\
9.76 \pm 2.86\end{array}$ & $\mathrm{P}=0.589, \mathrm{NS}$ \\
\hline $\begin{array}{l}\text { Non-diabetic patients } \\
\text { with CKD }\end{array}$ & $\begin{array}{l}\text { No. of cases-19) } \\
7.82 \pm 2.47\end{array}$ & $\begin{array}{l}\text { No. of cases -13) } \\
9.51 \pm 3.19\end{array}$ & $\mathrm{P}=0.106, \mathrm{NS}$ \\
\hline
\end{tabular}

There was statistical no significant difference of mean serum uric acid among hypertensivestage I and II with CKD patients ( $\mathrm{P}>0.05)$.In all CKD patients most of patients having hypertension as stages mentioned but will not reveal any significance when compare to SUA level.

Table 5: Distribution of cases according to proteinuria

\begin{tabular}{|l|l|l|}
\hline \multirow{2}{*}{ Groups } & Urine protein \\
\cline { 2 - 3 } & Positive & Negative \\
\hline Type 2 diabetes mellitus with CKD & $12(37.5 \%)$ & $20(62.5 \%)$ \\
\hline Non-diabetic patients with CKD & $24(75.0 \%)$ & $8(25.0 \%)$ \\
\hline
\end{tabular}

The Study observed that, there were $12(37.5 \%)$ cases of urine positives for protein Type 2 diabetes mellitus with CKD and $24(75.0 \%)$ cases were urine positive in Nondiabetic patients with CKD. 


\section{Discussion}

Studies have reported a strong association between elevated uric acid levels and obesity, metabolic syndrome, diabetes mellitus, hypertension, cardiovascular and renal disorders. Dharan KS, (2006), stated that Chronic kidney disease (CKD) is a serious condition associated with premature mortality, decreased quality of life, and increased health-care expenditures. Chronic kidney disease occurs when one suffers from gradual and usually permanent loss of kidney function over time. This happens gradually, usually over months to years. CKD is a worldwide health problem. ${ }^{[7]}$

Eknoyan G., in "Renaissace kidney- nephrology in and aboutsixteenth century (2011)" and"rememberance of the things past (2012)", explained that, throughout most of the history, the kidney has been considered as an accessory organ to the "economy" of nutrition, relegated to excretion of the "superfluidities" of food intake, and one prone to disease,although rarely susceptible to inflammation, occasionally ulceration, but principally affected by calculi and obstruction. ${ }^{[8]}$

Emeka A Nwankwo, William W Wudiri, Amos A Gadzama(2006) Study of Serum uric acidcorrelated with progression of nephropathy in a cohort of diabetic patients who had impaired kidney function at presentation in addition to them having satisfactory control of modifiable risk factors for progression such as for blood sugar, blood pressure, urinary protein excretion rate and serum lipids. ${ }^{[9]}$

Vahid Ansari et al. Yan et al(2015) reports that increased uric acid levels is a risk factor forthe were obtained development of diabetic nephropathy. Despite innate antioxidant activity of uric acid and increase of total antioxidant capacity and concentration of uric acid in diabetic patients with or without nephropathy, it cannot compensates the severity of oxidative stress. ${ }^{[10]}$

$\mathrm{CKD}$, with its high prevalence, morbidity and mortality, is an important public health problem. With, $3 \%$ of land mass, India hosts $17 \%$ of the Earth's population. Large numbers of patients below the poverty line, low gross domestic product, and low monetary allocations for health care have led to suboptimal outcomes. Moreover, CKD and other noncommunicable diseases have often been ignored in the face of persistent challenges from and competition for resources for communicable diseases and high infant and maternal mortality.

\section{Conclusion}

The Study observed that, there were $12(37.5 \%)$ cases of urine positives for protein Type 2 diabetes mellitus with CKD and $24(75.0 \%)$ cases were urine positive in Nondiabetic patients with CKD.

\section{References}

1. Niskanen LK, Laaksonen DE, NyyssönenK,et al. Uric acid level as a risk factor for cardiovascular and all-cause mortality in middle-aged men: a prospective cohort study. Arch Intern Med 2004;164:15461551.

2. Zoppini G, Targher G, Negri C, etal.Elevated serum uric acid concentrations independently predict cardiovascular mortality in type 2 diabetic patients. Diabetes Care 2009;32:1716-1720. .

3. National Kidney Foundation. K/DOQI clinical practice guidelines for chronic kidney disease: evaluation, classification, and stratification. Am J Kidney Dis 2012;39(Suppl. 1):S1-S266.

4. TangriN,Weiner DE. Uric acid, CKD, and cardiovascular disease: confounders, culprits, and circles. Am J Kidney Dis 2010;56:247-250.

5. Iseki $\mathrm{K}$, Oshiro $\mathrm{S}$, Tozawa $\mathrm{M}$, Iseki C,Ikemiya $\mathrm{Y}$, Takishita S. Significance of hyperuricemia on the early detection of renal failure in a cohort of screened subjects.Hypertens Res 2001;24:691-697.

6. Iseki $\mathrm{K}$, Ikemiya $\mathrm{Y}$, Inoue $\mathrm{T}$, Iseki $\mathrm{C}$, Kinjo $\mathrm{K}$, Takishita $\mathrm{S}$. Significance of yperuricemia as a risk factor for developing ESRD in a screened cohort. Am J Kidney Dis 2004;44:642-650.

7. Dharan KS, John GT, Neelakantan N, Korula A, BalakrishnanN,Kirubakaran MG, Jacob CK. Spectrum of severe chronic kidney disease in India: a clinicopathological study Natl Med J India. 2006 Sep-Oct;19(5):250-2.

8. Eknoyan G. The Renaissace kidney-nephrology in and about the sixteenth century. Semin Dial. 2012; 25(4): 451-459.

9. Emeka A Nwankwo, William W Wudiri, Amos A Gadzama. Serum Uric Acid Correlates With The Progression Of Nephropathy In Patients With Diabetes Mellitus. Pak J Med Sci October - December 2006 Vol. 22 No. 4 391-395.

10. Vahid Ansari, MehryarZargari, AtiehMakhlogh,ShivasaddatMirabedini, $\quad$ SaminehMotallebi. 2015.Association of Uric Acid with Antioxidant Capacity of Plasma in Patients with Type 2 Diabetic Nephropathy.ResMol Med 3(4):2327.

Copyright: (C) the author(s), 2019. It is an open-access article distributed under the terms of the Creative Commons Attribution License (CC BY 4.0), which permits authors to retain ownership of the copyright for their content, and allow anyone to download, reuse, reprint, modify, distribute and/or copy the content as long as the original authors and source are cited.

How to cite this article: Karan VN, Vishwanath VN. Clinical Profile of Patients with Chronic Kidney Disease. Acad. J Med. 2019;2(2):17578.

DOI: dx.doi.org/10.21276/ajm.2019.2.2.45

Source of Support: Nil, Conflict of Interest: None declared. 